\section{Morphine induced fighting and prior social experience $^{1}$}

DONALD H. THOR, DAVID L. HOATS, and CLAUDETTE J. THOR, E.R. Johnstone Training and Research Center, Bordentown, N.J.08505

Six groups of normally docile laboratory rats received morphine injections (to $600 \mathrm{mg} / \mathrm{kg} / \mathrm{day} /$, placebo injections, or no injections under social or isolated conditions for 6 days. Postwithdrawal intragroup fighting was then monitored for $168 \mathrm{~h}$ by automated recording of loud vocalizations. Morphine-treated groups spontaneously began sustained $(30 \mathrm{~h})$ fighting 3 days after terminal injections, with greatest fighting observed in the group receiving the drug under social conditions.

Spontaneous fighting among rats in their normal habitats occurs primarily between colonies or between species of rats (Barnett, 1963, 1967). Fighting behavior of Rattus norvegicus has also been described by Eibl-Eibesfeldt (1961) as species-specific, with similar components of ritualistic sparring preceding any biting attack. Scott (1966) has recently reviewed the research on the agonistic behavior of rats and mice. More recently, Scott (1968) concluded that social fighting in general has probably evolved from defensive responses. Lorenz (1966) has also emphasized aggression as a product of natural selection, and Moyer (1968) has reviewed the physiological basis for aggressive behavior.

The use of narcotic drugs to induce spontaneous fighting among common laboratory rats has been described by Boshka, Weisman, \& Thor (1966), Florea \& Thor (1968), Thor \& Teel (1968), and Thor (1969). When pretreated with morphine and placed in a group cage during withdrawal, laboratory rats will exhibit sustained fighting. Fighting begins approximately $75 \mathrm{~h}$ after the terminal dose of morphine and continues for 30-50 h.

Previous studies of withdrawal-induced fighting in rats have been conducted with Ss isolated in individual cages while receiving the drug. The present study examines the possible effect of socialization during the administration interval upon group behavior during withdrawal from morphine. Cohabitation during the morphine experience was anticipated to exert a restraint upon fighting during withdrawal.

Of further interest was the application of an automated device for sensing and recording fighting by rats in a group cage. groups, particularly during the early phase of recording, on the basis of discomfort due to repeated injections.

\section{SUBJECTS}

Fifty male rats of the Long-Evans hooded strain were received from a supplier (Rockland) in a weight range of $125-150 \mathrm{~g}$. All were placed in individual cages and remained in isolation for 6 weeks prior to the study. Thirty Ss were then selected within a group mid-weight range of $310-370 \mathrm{~g}$ and assigned randomly to six groups of five, with mean weights of $328-338 \mathrm{~g}$. Food and water were continuously available throughout the study.

\section{PROCEDURE AND APPARATUS}

Three groups were assigned randomly to the social condition and were placed in three group cages $(47 \times 37 \times 21 \mathrm{~cm})$. The other three groups were assigned to the isolate condition and remained in their individual cages.

One group in each condition then received morphine sulfate by intraperitoneal injection four times daily at 3-h intervals in gradually increasing dosage. Injections were given for 6 days in dosage noninjected and nonhandled control

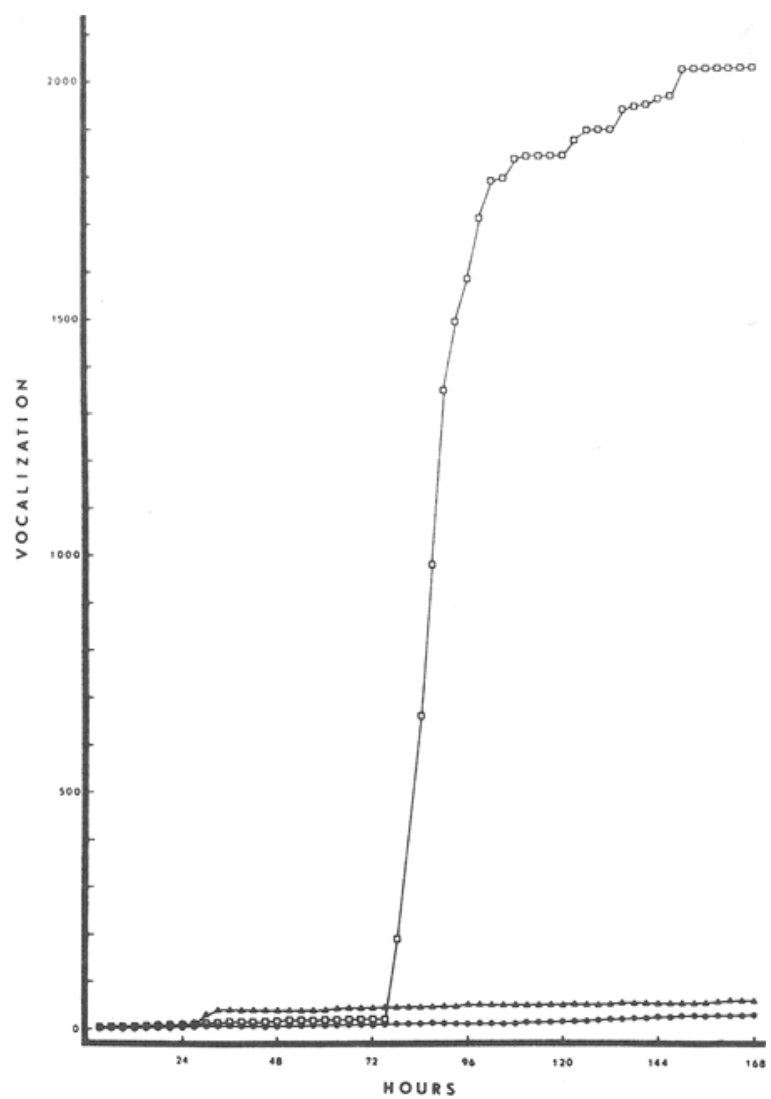

Fig. 1. Cumulative vocalization frequencies of social-experience groups over 7 days at 3-h intervals. The morphine-treated group is indicated by square data points (Group 1). Nonmorphine-treated placebo and nonhandled controls are indicated by circle and triangle data points, repsectively (Groups 3 and 5 ). 
ranging from 10 to $150 \mathrm{mg} / \mathrm{kg}$ per dose; on the last day, each $S$ received a total of $600 \mathrm{mg} / \mathrm{kg}$. Solutions were prepared fresh daily from hypodermic tablets (Lilly HT No. 134) dissolved in sterile water for injection (Abbott).

One group in each condition received placebo injections of volumetrically equivalent normal saline at the same time of day. The two remaining groups received no injections and were not handled.

Morphine-treated experimental groups of social and isolate conditions were designated as Group 1 and Group 2, respectively; social and isolate placebo control groups were designated Group 3 and Group 4; social and isolate controls receiving no injections were designated Group 5 and Group 6.

Within $10 \mathrm{~min}$ after terminal injections, groups were placed in six identical experimental cages (random assignment) to monitor vocalization during induced fighting. Each cage was $30 \times 30 \times 20 \mathrm{~cm}$ with a small crystal lapel microphone mounted in the center of the cage roof (acoustic tile). Six voice-operated relays (Eico), with separate power supplies, were used to detect loud squeals and actuate pens on an operations recorder (Esterline Angus at $1.9 \mathrm{~cm} / \mathrm{min}$ ). Sensitivity was so adjusted that only relatively loud squeals of $90 \mathrm{~dB}$ or greater were sensed. The relay units were calibrated for equivalent sensitivity by use of a stereo-tape playback of previously recorded fighting.

\section{RESULTS}

Recording was terminated after $168 \mathrm{~h}$ when it was evident that all fighting had ceased. Pips on the recorded tape were tabulated for each group and were presented as cumulative frequencies for social groups (Fig. 1) and isolate groups (Fig. 2). Inspection of Fig. 1 reveals a distinctive difference in the vocalization rate of the morphine-treated group when compared with control groups. Group 1 emitted a total of 2,037 responses, whereas Groups 3 and 5 emitted only 34 and 62 total responses, respectively. The evident change in rate of vocalization by Group 1 began at $75 \mathrm{~h}$ after terminal morphine and continued for $24 \mathrm{~h}$.

A less abrupt but more prolonged duration of vocalization accompanying fighting occurred in the morphine-treated isolates (Group 2), as seen in Fig. 2. Time of maximum vocalization, however, corresponds with that of Group 1 and occurred after Group 4 (placebo-isolates) had nearly ceased responding.

The hypothesis of maximum fighting by morphine-treated isolates was not supported since Group 2 emitted less than a third as many responses as Group 1. The

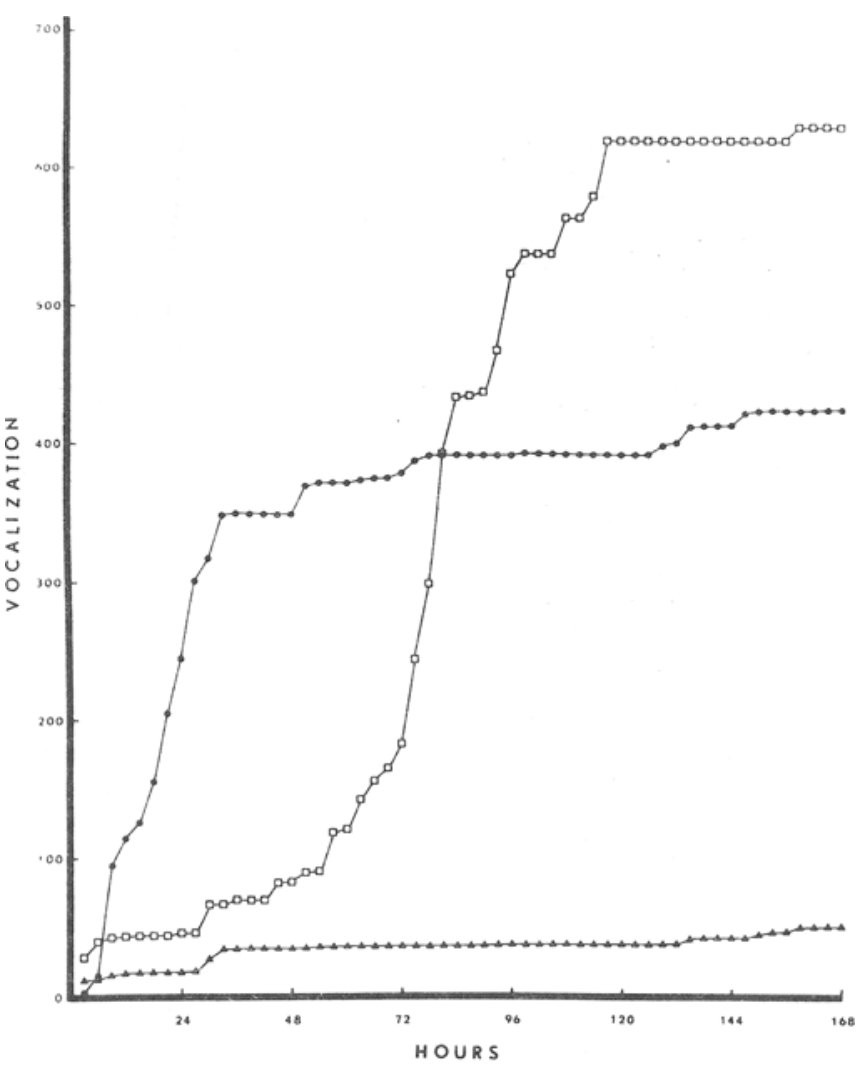

Fig. 2. Cumulative vocalization frequencies of isolation groups. Square, circle, and triangle data points distinguish morphine, placebo, control, and nonhandled control groups (Groups 2, 4, and 6), as in Fig. 1.

remaining hypotheses were all generally confirmed.

Visual observation of fighting indicated typical posturing and allied movements as described for rat fighting behavior by Barnett (1963) and other investigators using other means of induction, such as electric shock (Ulrich \& Azrin, 1962). Biting was occasionally observed in Groups 1 and 2 , but intensity of fighting was not as great as indicated by Thor (1969) when an amphetamine was used to trigger fighting during morphine withdrawal. Fighting was not lethal or severely traumatic and may thus be considered primarily ceremonial or ritualistic (Eibl-Eibesfeldt, 1961).

\section{DISCUSSION}

Social grouping during morphine administration appears to increase fighting behavior during morphine withdrawal. Placebo and nonhandled control groups given the same social experience but excluding the morphine exhibit insignificant fighting behavior in comparison (Fig. 1).

Control Ss, given placebo injections during isolation, also exhibit sustained fighting during the first and second days after grouping (Fig. 2). Placebo isolates thus differ from all other controls including the social placebo group, which differed only in social experience. Apparently socialization acts to inhibit fighting due to irritation from injections. Early fighting due to injection irritability is perhaps not evident in morphine-treated groups due to residual analgesia from relatively high terminal dosage.

The effect of social grouping during the injection interval thus appears to inhibit fighting in the placebo controls and promote fighting among morphine-treated Ss. One explanation for opposite effect may be the inhibition to fighting resulting from the on-going formation of dominance-subordination relationships in the drug-treated isolate group. Once such relationships are formed, as may occur in the social condition, challenges to individual status during withdrawal may lead to less inhibited aggressive response. The lack of fighting in the nondrug and nonhandled Ss (Groups 5 and 6) support the contention that irritation due to injections and drug withdrawal were the primary causes of fighting. Since only the morphine-treated groups evidenced fighting 
after $75 \mathrm{~h}$, it can be concluded that the withdrawal syndrome from the prior drug administration was the principal contributor to the observed fighting.

The delay in onset of vigorous fighting by the morphine groups is relatively uniform and corresponds with the delay noted by Thor \& Teel (1968), who used terminal dosages of 100,200 , and $400 \mathrm{mg} / \mathrm{kg} /$ day. The interval prior to onset, as well as the duration, of vigorous and sustained fighting may thus be independent of prior dosage level above the threshold for fighting. The more apparent explanation is that fighting is due to emotional hyperirritability that parallels peak withdrawal distress. Time of maximum distress according to prior dosage, however, is presently unknown for the rat, but observation of a number of groups at a range of terminal dosages of morphine ( $50-600 \mathrm{mg} / \mathrm{kg} / \mathrm{day}$ ) supports the consideration that peak of withdrawal stress occurs between 3 and 4 days after the terminal dose.

Continuous and automated monitoring of group cages for loud vocalization appears to be a useful method for unambiguous recording of spontaneous drug-induced fighting behavior in rats. REFERENCES

BARNETT, S. A. The rat: $A$ study in behavior. Chicago: Aldine, 1963.

BARNETT, S. A. Rats. Scientific American, $1967,216,78-85$.
BOSHKA, S. C., WEISMAN, H. M., \& THOR, D. H. A technique for inducing aggression in rats utilizing morphine withdrawal. Psychological Record, 1966, 16, 541-543.

EIBL-EIBESFELDT, I. The fighting behavior of animals. Scientific American, 1961, 205, 112-122.

FLOREA, J., \& THOR, D. H. Drug withdrawal and fighting in rats. Psychonomic Science, $1968,12,33-34$.

LORENZ, K. On aggression. New York: Harcourt, Brace \& World, 1966.

MOYER, K. E, A preliminary physiological model of aggressive behavior. Paper presented at the meeting of the American Association for the Advancement of Science, Dallas, December 1968.

SCOTT, J. P. Agonistic behavior of mice and rats: A review. American Zoologist, 1966, 6, 683-701.

SCOTT, J. P. Theoretical issues concerning the origin and causes of fighting. Paper presented at the meeting of the American Association for the Advancement of Science, Dallas, December 1968.

THOR, D. H. Chemical induction of traumatic fighting. Proceedings of the 77 th annual convention of the American Psychological Association, 1969, Part 2, 883.

THOR, D. H., \& TEEL, B. G. Fighting of rats during post-morphine withdrawal: Effect of prewithdrawal dosage. American Journal of Psychology, 1968, 81, 439-442.

ULRICH, R. E., \& AZRIN, N. H. Reflexive fighting in response to aversive stimulation. Journal of the Experimental Analysis of Behavior, 1962, 5, 511-520.

\section{NOTE}

1. This work was supported in part by United States PHS Grant MH 17402-01.

\section{Extinction of free-operant avoidance behavior using a three-ply schedule}

\section{DAVID D. BURNSTEIN, State University College of New York at Potsdam, Potsdam, N.Y. 13676}

Four rats were trained on a three-ply avoidance schedule of $R-S 9.5 \quad S-S 2$, $R-S 15 \quad S-S 5$, and $R-S 30 \quad S-S 15$. An extinction leg was then substituted for one of the avoidance legs. Results indicated that by using this procedure, extinction took place within the 1 -h leg. Responding during the extinction was a function of the strength of the avoidance response without respect to any of the avoidance schedules. The data indicated only one case of a discrimination based on repeated extinction-avoidance training.

The usual extinction procedure for avoidance training is the removal of the shock from the experimental situation. Studies using this procedure have found differences in the persistence of the avoidance behavior. Sidman (1955) found no performance decrement in 15-min environment cubicle, was used. Experimental contingencies were controlled by standard programming equipment. Data were recorded on counters and a Gerbrands cumulative recorder. A shock of $2-\mathrm{mA}$ intensity for a $0.2-\mathrm{sec}$ duration was delivered by a Grason-Stadler shock generator. Schedule changes within a session were made manually.

\section{PROCEDURE}

The Ss were run in 3-h sessions every other day except Sunday. The training schedule was a three-ply free operant avoidance schedule consisting of 1-h legs of R-S 9.5 S-S 2, R-S 15 S-S 5, and R-S 30 S-S 15. The legs of the schedule were counterbalanced across sessions. Ss had from 180 to $219 \mathrm{~h}$ on the training schedule.

\section{First Extinction}

One of the avoidance legs of the three-ply schedule was replaced by an extinction leg. The legs were counterbalanced over four sessions, but with the extinction leg in either the second or third position. After four sessions with an extinction probe, the training schedule was run for two sessions. The extinction procedure was repeated until each of the avoidance schedules had been replaced by an extinction probe. A total of 12 extinction sessions were run under this procedure.

\section{Second Extinction}

Following the first extinction, the procedure was changed so that in each session a different avoidance leg was replaced by the extinction leg. The legs were counterbalanced across sessions, with the extinction leg occurring in either the second or third position. A total of 12 extinction sessions were run under this procedure.

\section{RESULTS AND DISCUSSION}

An indication of the baseline avoidance behavior can be seen from the pre-15-min extinction intervals in Fig. 1. The median responses during the $15 \mathrm{~min}$ before the extinction leg differ for each $S$, but the inverse relationship between $R-S$ intervals and median response is the same for each $S$. The median response is highest for the R-S 9.5 and lowest for the R-S 30.

The median response for each 15-min segment of the 1 -h extinction leg is shown in Fig. 1. For $S 4$ and $S 6$, these curves decrease as a function of time into the extinction leg. The trend is the same regardless of the preceding avoidance schedule. For S 2, only the extinction when preceded by an R-S 30 deviates from the decreasing median response pattern and then only for the first $15 \mathrm{~min}$ of 